\title{
TRADUCCIÓN DE CULTUREMAS, UNA NUEVA TENDENCIA EN LOS ESTUDIOS DE LA TRADUCCIÓN
}

\author{
Najlaa Kounitrate \\ Escuela Superior Rey Fahd de Traducción - Marruecos \\ http://dx.doi.org/10.18778/8220-201-4.11
}

\section{Resumen}

Este trabajo se centra en la traducción de los culturemas considerados como unidades lingüísticas marcadas culturalmente. Inicia con dar una definición extensa del término culturema, luego analiza la variación, tanto de sus clasificaciones como de las técnicas propuestas para traducir estas palabras culturales, y al final da unos ejemplos de culturemas sacados de la obra Pedro Páramo de Juan Rulfo y de sus tres traducciones árabes, haciendo hincapié en las dificultades encontradas.

Palabras clave: Culturema, Traducción, Cultura, Pedro Páramo, Árabe.

\section{1.}

\section{El término culturema}

Últimamente, las teorías culturales están ganando terreno en los estudios de la traducción a costa de las teorías lingüísticas que eran el punto de partida del análisis de los textos traducidos.

Este cambio, que es el resultado de los nuevos estudios que consideran que la traducción es un acto de comunicación intercultural, incitó a los teóricos a crear diferentes denominaciones, clasificaciones y técnicas de traducción de los elementos culturales que se identifican en los textos objeto de traducción. 
El primero en fijarse en dichos elementos es el traductólogo bíblico Eugene Nida, quien en su artículo "Linguistics and Ethnology in Translation Problems" (1945) destaca la relación entre la traducción y la cultura y la importancia de este tipo de unidades lingüísticas como componentes clave en la translación.

Hasta el momento, el origen del término culturema no es conocido, aunque se lo atribuye a Vermeer (1983), quien lo define como: "a social phenomenon of a culture $\mathrm{X}$ that is regarded as relevant by the members of this culture and, when compared with a corresponding social phenomenon in a culture $\mathrm{Y}$, is found to be specific to culture X." (Vermeer, 1983: 8 cit. por Nord, 1997: 34).

Vermeer introduce el término culturema para referirse a los elementos de distintos tipos que se encuentran en una cultura determinada. Su interés por dicho elemento cultural se debe a la dificultad que representa en la traducción, ya que está estrechamente relacionado con la cultura origen.

Por su parte, la autora española Hurtado Albir (2001: 611) lo redefine de la siguiente manera:

sirve para referirnos a los elementos culturales característicos de una cultura presentes en un texto y que, por su especificidad, pueden provocar problemas de traducción. Esos elementos culturales, que pueden aparecer marcados en un texto de modo más o menos explícito, son, como hemos visto, de diversa índole: relacionados con la ecología, lo material, lo social, lo religioso, lo paralingüístico, etc.

Molina Martínez (2006: 79) explica de manera sencilla que el término se refiere a "un elemento verbal o paraverbal que posee una carga cultural específica en una cultura y que al entrar en contacto con otra cultura a través de la traducción puede provocar un problema de índole cultural entre los textos origen y meta”. 


\section{1.}

\section{Denominaciones de los elementos culturales}

En la traductología, para aludir a los elementos pertenecientes a una cultura determinada encontramos varias propuestas terminológicas: Realia (Vlakhov y Florin, 1970); Cultural Words (Newmark, 1988); Culturema (Veermer, 1983); Referentes/ Referencias culturales (Mayoral, 1994).

A continuación, presentamos un cuadro que incluye las principales denominaciones con sus correspondientes autores:

Tabla 1. denominaciones de los elementos culturales

\begin{tabular}{l|l}
\multicolumn{1}{c|}{ CULTUREMA } & $\begin{array}{c}\text { OKSAAR, VERMEER, NORD, } \\
\text { HURTADO ALBIR, MOLINA, } \\
\text { LUQUE NADAL }\end{array}$ \\
\hline Elemento cultural & Nida \\
\hline Foco Cultural, Cultural Words & Newmark \\
\hline Indicadores culturales & Nord \\
\hline Puntos Ricos & Agar \\
\hline Realia & Vlakhov y Florin; Escuela Eslava \\
\hline Referencias culturales & Mayoral \\
\hline Referente cultural & Marco, Santamaría \\
\hline
\end{tabular}

\section{2.}

\section{Clasificación de los elementos culturales}

Para clasificar los elementos culturales encontramos diferentes propuestas como la de Nida (1945), la de Santamaría (2001), la de Molina (2006).

Vlakhov y Florin (1970) dividen el término realia, en cuatro ámbitos: 1) geográficos y etnográficos, 2) folklóricos y mitológicos, 3) objetos cotidianos y 4) sociales e históricos (organización política, movimientos sociales, centros de enseñanza y clases sociales). 
Nida (1975) los divide en cinco aspectos: 1) ecología (flora, fauna, etc.); 2) cultura social (trabajo y tiempo libre); 3) cultura religiosa; 4) cultura lingüística que se subdivide en otras categorías: la fonología, morfología, sintaxis y léxico; y 5) cultura material: objetos, productos, artefactos (comida y bebida).

Por su parte, Molina (2001: 91-98) divide el culturema en cuatro ámbitos culturales, una clasificación que nos parece pertinente para nuestra investigación:

1. Medio natural: flora, fauna, fenómenos atmosféricos, climas, vientos, topónimos.

2. Patrimonio cultural: personajes, religión, objetos, medios de transporte.

3. Cultura social: hábitos sociales, saludos, gestos.

4. Cultura lingüística: refranes, insultos, metáforas.

A estos cuatro ámbitos culturales, Molina añade los falsos amigos culturales y las injerencias culturales.

\section{2.}

\section{Traducción y culturema}

Muchos traductólogos han analizado la relación estrecha entre la traducción y la cultura, como Vidal Claramonte (1995) que considera que la cultura es una unidad de traducción, o bien, Katan (1999) que afirma que se traducen culturas no sólo textos.

De acuerdo con Hurtado Albir (2001: 614-615), hay seis elementos que determinan las elecciones traductivas de los culturemas: "1) el tipo de relación entre dos culturas, 2) el género textual en que se inserta, 3) la función del culturema en el TO, 4) la naturaleza del culturema, 5) las características del destinatario, y 6) la finalidad de la traducción".

Por su parte, Luque Toro (2006: 217) opina acerca de la traducción de los culturemas: "No se trata de imponer el sistema de valores de una cultura en otra, (Susan Basnett, Translation Studies. London: Routledge 2005, p. 30), sino de encontrar la expresión idiomática que tenga el mismo significado". 


\section{1.}

\section{Problemas de traducción}

El culturema presenta un gran problema a la hora de querer comprender su significado pragmático estrechamente relacionado con la cultura meta, y desde luego, traducirlo a una lengua y cultura diferentes.

Su mayor dificultad reside en cómo traducir los elementos que no tienen equivalentes en la cultura meta, teniendo en cuenta la distancia y el vacío culturales.

Otro problema de traducción de este tipo de términos es cuando el traductor no tiene conocimientos sólidos acerca de la cultura y lengua meta, e intenta traducir una referencia cultural que no comprende.

A veces, el traductor no encuentra en la cultura meta un culturema que podría transmitir el mismo mensaje del culturema original, por ello, como solución, recurre a sustituirlo por una paráfrasis que tiene casi el mismo sentido; sin embargo, esta solución no siempre es pertinente dada la complejidad del culturema.

\section{2.}

\section{Técnicas de traducción}

Para traducir los elementos culturales encontramos un abanico de técnicas propuestas por varios traductólogos.

Vinay y Darbelnet (1958) son los pioneros en definir y clasificar los procedimientos técnicos de traducción, que tienen como objetivo explicar los mecanismos que entran en juego al pasar de una lengua a otra. Dichos mecanismos se obtienen en general a través del análisis contrastivo de dos sistemas lingüísticos distintos, salvo la adaptación, porque su criterio principal de equivalencia es situacional y no lingüístico.

Posteriormente, los traductores bíblicos representados por Nida, Taber y Margot proponen unas técnicas para la transferencia cultural en caso de la inexistencia de un equivalente en la lengua de llegada. Así, Nida (1964) propone tres tipos: adición, sustracción, alteración y notas a pie de página. 
En cuanto a Newmark (1988), este investigador indica que hay 12 procedimientos de traducción: el préstamo, el equivalente cultural, neutralización (explicación del referente).

En nuestro trabajo proponemos una clasificación de técnicas orientadas al análisis de los culturemas del español al árabe, basándonos en la propuesta de Molina (2006: 100-101), quien propone una clasificación de 18 técnicas de traducción:

Adaptación: consiste en reemplazar un elemento cultural propio de la cultura de origen por otro propio de la cultura meta. Ejemplo: traducir عقبقة, un rito musulmán que se realiza el séptimo día después del nacimiento y que consta de una celebración que incluye el sacrificio de un cordero, cortar el pelo al bebé y si es niño circuncidarlo a partir del día después de la celebración, por bautizo.

Ampliación lingüística: consiste en añadir elementos lingüísticos. Se opone a la técnica de compresión lingüística. Ejemplo: traducir al castellano la expresión inglesa no way por de ninguna de las maneras, en vez de utilizar una expresión con el mismo número de palabras como en absoluto.

Amplificación: consiste en introducir precisiones no formuladas en el texto original: informaciones, paráfrasis explicativas, etc. Incluye las notas del traductor. Se opone a la técnica de reducción. Ejemplo: traducir del árabe al castellano Ramadán por Ramadán, mes del ayuno para los musulmanes.

Calco: consiste en traducir literalmente una palabra o sintagma extranjero; puede ser léxico y estructural. Ejemplo: traducir el saludo musulmán السلام عليكم por la paz sea contigo.

Compensación: consiste en introducir en otro lugar del texto un elemento de información o un efecto estilístico que no ha podido reflejarse en el mismo sitio en que está situado en el texto original. Compresión lingüística: consiste en sintetizar elementos lingüísticos. Se opone a la técnica de ampliación lingüística. Ejemplo: traducir del castellano la frase interrogativa inglesa Yes, so what? por $¿ Y$ ?, en vez de una expresión con el mismo número de palabras como ¿Sí, y qué?

Creación discursiva: consiste en establecer una equivalencia efímera totalmente imprevisible fuera de contexto. Esta técnica se 
usa a menudo a la hora de traducir los títulos de obras y películas. Ejemplo: la novela de Mohammed Al Asfar فرحة (literalmente, alegría), titulada en español La increíble historia de la imposible caza y captura de la alegría.

Descripción: consiste en reemplazar un término o expresión por la descripción de su forma y/o función. Ejemplo: traducir sacristía por غرفة الدقدسات.

Equivalente acuñado: consiste en utilizar un término o expresión reconocidos (por el diccionario, por el uso lingüístico) como equivalente en la lengua de llegada. Ejemplo: traducir la misa por لقدس.

Generalización: consiste en utilizar términos más generales o neutros. Se opone a la técnica de particularización. Ejemplo: traducir la velación por الطقوس.

Modulación: consiste en realizar un cambio de punto de vista, de enfoque o de categoría de pensamiento en relación con la formulación del texto original; puede ser léxica y estructural. Por ejemplo, la traducción francesa de la expresión árabe هذا بثلج صدري por ça me réchauffe le coeur. En la cultura de partida, la alegría de recibir una buena noticia se asocia con el frío que se añora en el clima caluroso y cálido de la cultura árabe. Sin embargo, en la cultura meta, esta expresión se asocia con el calor.

Particularización: consiste en utilizar términos más precisos o concretos. Se opone a la técnica de generalización. Ejemplo: traducir أعدال أدبية por novelas.

Préstamo: consiste en integrar una palabra o expresión de otra lengua sin modificarla. Ejemplo: traducir capitán por كابتن, general por جنرال, coronel por كولونيل.

Reducción: consiste en suprimir en el texto meta algún elemento de información presente en el texto original, por completo o sólo una parte. Ejemplo: eludir a la ceremonia musulmana que se realiza por el recién nacido para ponerle nombre por aqiqah.

Substitución: consiste en cambiar elementos lingüísticos por paralingüísticos (entonación, gestos), o viceversa. Ejemplo: traducir el gesto árabe de llevarse la mano al corazón por gracias. 
Traducción literal: consiste en traducir palabra por palabra un sintagma o expresión. Ejemplo: traducir echar tierra al asunto por ألقى التراب على القضية.

Transposición: consiste en cambiar la categoría gramatical. Ejemplo: traducir al castellano He will soon be back por No tardará en venir en vez de Estará de vuelta pronto.

Variación: consiste en cambiar elementos lingüísticos o paralingüísticos (entonación, gestos) que afectan a aspectos de la variación lingüística: cambios en el tono textual, el estilo, el dialecto social, el dialecto geográfico, etc. Ejemplo: introducción o cambios de marcas dialectales para la caracterización de personajes en la traducción teatral, cambios de tono en adaptaciones de novelas para niños, etc.

\section{3.}

\section{Ejemplos de traducción}

En este apartado, vamos a analizar unos ejemplos de culturemas sacados del original y de las tres traducciones árabes de la obra mexicana Pedro Páramo de Juan Rulfo. Para ello, seguiremos una metodología descriptiva-comparativa con el fin de estudiar las técnicas empleadas para traducir los elementos culturales.

Para la elaboración de nuestro trabajo, hemos seguido las pautas siguientes:

1. Extraer los culturemas.

2. Identificar, comparar y clasificar las técnicas de traducción usadas por los traductores, siguiendo la clasificación de las técnicas de traducción propuesta por Molina (2001-2006).

Como se sabe, la obra principal de nuestro corpus es la novela de Juan Rulfo. Para facilitar la comprensión y la puesta en marcha de nuestro trabajo, hemos elegido la cuarta edición de José Carlos González Boixo publicada en Cátedra en 1986, porque incluye anotaciones y explicaciones del léxico mexicano rural.

En cuanto a las traducciones árabes, hemos elegido las siguientes: la versión de Sāleḩ Almāniy (2013) [TM1], la versión 
de Sherīn 'Ṣmat (2013) [TM2] y la versión de Maruān Ibrāhīm (1990) [TM3].

- Tortilla

\section{TO: 124}

Encontré un trozo de cecina y encima de las brasas unas tortillas ${ }^{(*)}$

${ }^{(*)}$ Tortilla: Amer., pan en forma de disco como del diámetro de un plato, por lo común de masa de maíz, cocida en comal, que constituye la base de la alimentación de la gente pobre, del campesinado y del indígena, usando mucho también en la mesa de cualquier categoría social.

\begin{tabular}{|c|c|c|}
\hline $\begin{array}{l}\text { TM1: } 90 \\
\text { Reducción }\end{array}$ & وأقراص العدت قطعة من اللحم المقدد وبعض الموقد. & $\begin{array}{l}\text { Encontré un trozo de } \\
\text { cecina y unas tortillas } \\
\text { encima de las brasas. }\end{array}$ \\
\hline $\begin{array}{l}\text { TM2: } 115 \\
\text { Reducción }\end{array}$ & والموقد. & $\begin{array}{l}\text { Encontré un trozo de } \\
\text { cecina y una tortilla } \\
\text { encima de las brasas. }\end{array}$ \\
\hline $\begin{array}{l}\text { TM3: } 125 \\
\text { Reducción }\end{array}$ & والعجة على قطعة من النار. & $\begin{array}{l}\text { Encontré un trozo de } \\
\text { cecina y un poco de } \\
\text { tortilla encima de las } \\
\text { brasas. }\end{array}$ \\
\hline
\end{tabular}

\section{TO : 166}

Sólo se les oyó sorber el chocolate cuando les trajeron el chocolate, y masticar tortilla tras tortilla cuando les arrimaron los frijoles.

\begin{tabular}{|c|c|c|}
\hline $\begin{array}{l}\text { TM1: } 145 \\
\text { Reducción }\end{array}$ & 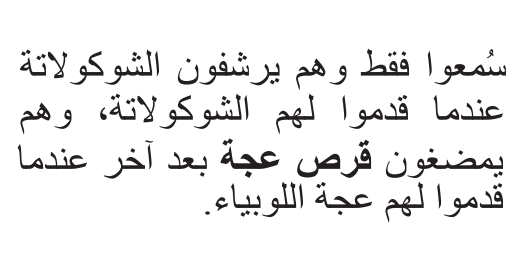 & $\begin{array}{l}\text { Sólo se les oyó sorber } \\
\text { el chocolate cuando les } \\
\text { trajeron el chocolate, } \\
\text { y masticar tortilla tras } \\
\text { otra cuando les dieron } \\
\text { tortillas de frijoles. }\end{array}$ \\
\hline $\begin{array}{l}\text { TM2: } 178 \\
\text { Reducción }\end{array}$ & 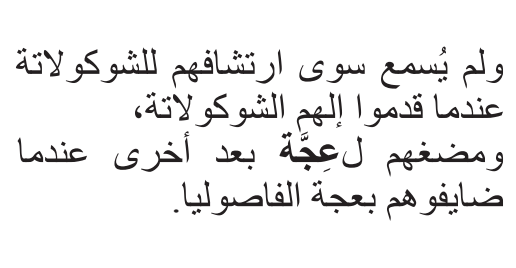 & $\begin{array}{l}\text { Sólo se les oyó sorber } \\
\text { el chocolate cuando les } \\
\text { trajeron el chocolate, } \\
\text { y masticar tortilla tras } \\
\text { otra cuando les dieron } \\
\text { tortilla de frijoles. }\end{array}$ \\
\hline
\end{tabular}




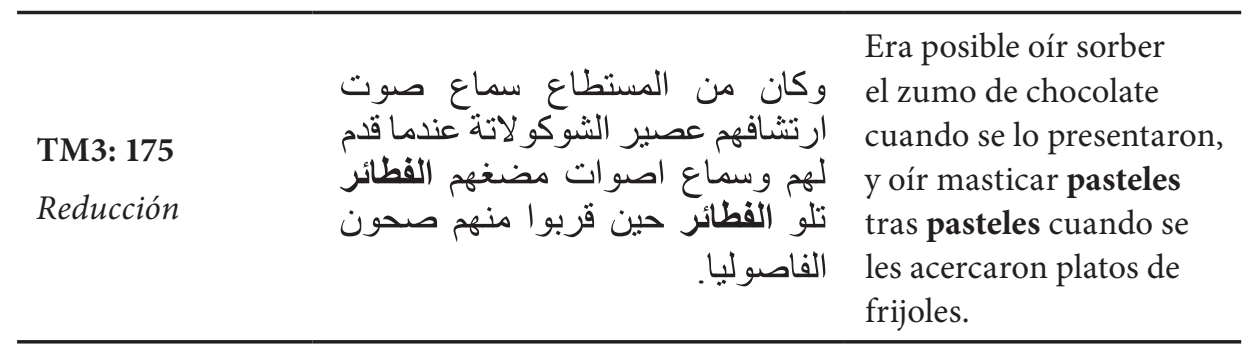

La tortilla es un término polisémico. Según el Diccionario de Americanismos hay varios tipos de tortillas: la española hecha a base de huevos y patatas; la mexicana, a la que se refiere Juan Rulfo, que es un tipo de pan preparado con harina de maíz $y$ a veces de trigo; la ecuatoriana elaborada con puré de patatas y queso...

En este contexto y teniendo en cuenta que la novela transcurre en México, tortilla alude a قرص من الذرة o رقاقة من الذرة.

"عجة " Los tres textos meta han traducido el culturema por (tortilla española), " فطائر" (pasteles). Se trata de dos soluciones que nos parecen extrañas dado el contexto del fragmento, por eso, clasificamos las técnicas empleadas como una reducción, porque podrían provocar un malentendido en la comprensión y recepción del culturema.

Opinamos que el uso de dichas soluciones se debe a un lapsus o descuido por parte de los traductores árabes.

- Pasársele las canelas a uno

TO: 142

Se me pasaron las canelas. Me dieron de beber tanto, que hasta me volví payasa.

\begin{tabular}{|c|c|c|}
\hline $\begin{array}{l}\text { TM1: } 113 \\
\text { Traducción literal }\end{array}$ & كرواً عليّ بالقرفة. لقد أعطوني شراباً & $\begin{array}{l}\text { Se me pasaron las } \\
\text { canelas. Me dieron de } \\
\text { beber tanto, que hasta } \\
\text { me volví payasa. }\end{array}$ \\
\hline $\begin{array}{l}\text { TM2: } 141 \\
\text { Traducción literal }\end{array}$ & كريراً، حتى أصبيّ القرفة. جعلوني أشرب مهرجة. & $\begin{array}{l}\text { Se me pasaron las } \\
\text { canelas. Me hicieron } \\
\text { beber tanto, que hasta } \\
\text { me volví payasa. }\end{array}$ \\
\hline
\end{tabular}


TM3: 145

Traducción literal

+ Préstamo
Me dieron la bebida de

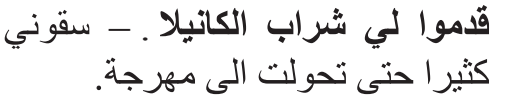
canela. Me dieron de beber tanto, que hasta

me volví payasa.

Según el Diccionario de Hispanoamericanismos la expresión pasársele las canelas a uno significa en México "beber demasiado". Asimismo, en el Diccionario Clave una de las acepciones del verbo pasar(se) es: "excederse o sobrepasar un límite: no suele beber, pero hoy se ha pasado".

Los TM1 y TM2 han optado por utilizar una traducción literal

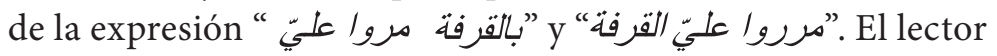
árabe entenderá que se trata de una bebida a base de canela, por lo que desaconsejamos la traducción literal en este caso.

Por su parte, el TM3 ha usado la traducción literal y el préstamo de la palabra canela “قدمو لي شراب الكانيلا", que tampoco vemos que sea una buena vía para solucionar el problema de equivalencia y comprensión.

\section{- Sacristía}

\section{TO: 91}

Entró en la sacristía, se echó en un rincón, y allí lloró de pena y de tristeza hasta agotar sus lágrimas.

\begin{tabular}{|c|c|c|}
\hline $\begin{array}{l}\text { TM1: } 49 \\
\text { Descripción }\end{array}$ & 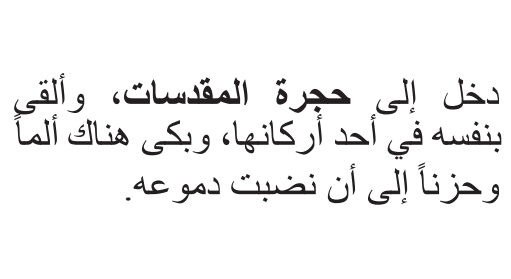 & $\begin{array}{l}\text { Entró en la cabina de } \\
\text { los ornamentos sacros, } \\
\text { se echó en un rincón, } \\
\text { y allí lloró de pena y de } \\
\text { tristeza hasta agotar sus } \\
\text { lágrimas. }\end{array}$ \\
\hline $\begin{array}{l}\text { TM2: } 67 \\
\text { Descripción }\end{array}$ & 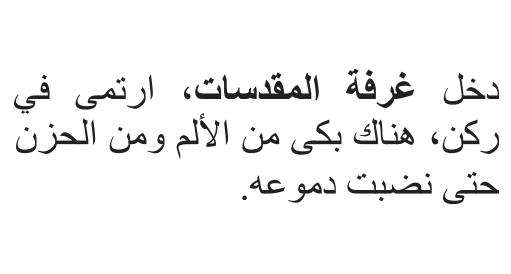 & $\begin{array}{l}\text { Entró en la habitación } \\
\text { de los ornamentos } \\
\text { sacros, se echó en un } \\
\text { rincón, y allí lloró de } \\
\text { pena y de tristeza hasta } \\
\text { agotar sus lágrimas. }\end{array}$ \\
\hline
\end{tabular}




\section{Entró en la habitación}

TM3: 88

دخل الغزفة المقدسة و انزوى في احد الإن المدي

sacra, se echó en un

Descripción rincón, y allí lloró de pena y de tristeza hasta agotar sus lágrimas.

TO: 144

Se levantó del confesionario y se fue derecho a la sacristía.

\begin{tabular}{|c|c|c|}
\hline $\begin{array}{l}\text { TM1: } 166 \\
\text { Descripción }\end{array}$ & نهضاشرة عن منصة اللى حجرة المقدسات اف ومضى & $\begin{array}{l}\text { Se levantó del } \\
\text { confesionario y se fue } \\
\text { derecho a la cabina de } \\
\text { los ornamentos sacros. }\end{array}$ \\
\hline $\begin{array}{l}\text { TM2:144 } \\
\text { Descripción }\end{array}$ & نمينا إلى غرفة كرسي الاعتر اف و اتجهات. & $\begin{array}{l}\text { Se levantó del } \\
\text { confesionario y se } \\
\text { fue a la derecha a la } \\
\text { habitación de los } \\
\text { ornamentos sacros. }\end{array}$ \\
\hline $\begin{array}{l}\text { TM3: } 147 \\
\text { Descripción }\end{array}$ & نهاشرة عن كرسي اللى الخزانة المقرة اف واتجهه & $\begin{array}{l}\text { Se levantó del } \\
\text { confesionario y se fue } \\
\text { derecho al armario } \\
\text { sacro. }\end{array}$ \\
\hline
\end{tabular}

A pesar de que el árabe ya cuenta con un equivalente acuñado los tres textos meta en los dos ejemplos coinciden en utilizar la descripción para trasladar el culturema cristiano sacristía.

Seguro que los tres traductores han llevado el texto hacia el lector parafraseando y facilitando el significado del culturema, sin embargo, la palabra religiosa ha perdido su connotación cultural. 
TO : 155

Un cedazo para colar el atole ${ }^{(*)}$.

${ }^{(*)}$ Atole: (del nahua atolli) Méx., bebida con maíz cocido y disuelto en agua hervida; también se hace con leche. Es un alimento muy usado en México.

\begin{tabular}{|c|c|c|}
\hline TM1: 131 & منخل لتصفية الأتولي(*). & $\begin{array}{l}\text { Un cedazo para colar el } \\
\text { atole }^{(*)} \text {. }\end{array}$ \\
\hline $\begin{array}{l}\text { Préstamo }+ \\
\text { Amplificación }\end{array}$ & الذرة)الأتولي: مشروب مكسيكي يُقطر من & $\begin{array}{l}\left.{ }^{*}\right) \text { Atole: bebida } \\
\text { mexicana hecha a base } \\
\text { de maíz. }\end{array}$ \\
\hline $\begin{array}{l}\text { TM2: } 161 \\
\text { Préstamo }\end{array}$ & & $\begin{array}{l}\text { Un cedazo para colar el } \\
\text { atole. }\end{array}$ \\
\hline $\begin{array}{l}\text { TM3: } 161 \\
\text { Préstamo + } \\
\text { Amplificación }\end{array}$ & 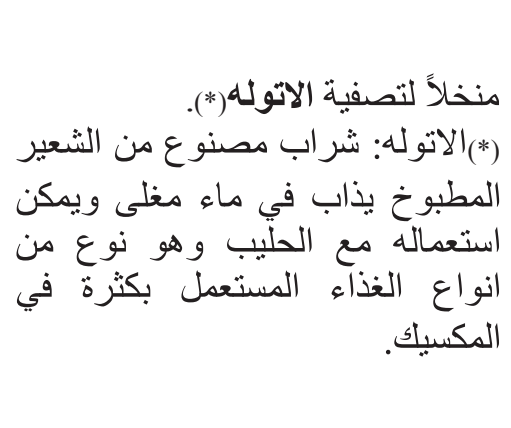 & $\begin{array}{l}\text { Un cedazo para colar el } \\
\text { atole }^{(*)} \text {. } \\
\left(^{*} \text { Atole: bebida hecha }\right. \\
\text { con cebada cocida } \\
\text { y disuelta en agua } \\
\text { hervida; también se } \\
\text { hace con leche. Es un } \\
\text { alimento muy usado en } \\
\text { México. }\end{array}$ \\
\hline
\end{tabular}

El atole es una bebida espesa que se hace con maíz cocido y disuelto en agua hervida. En México, es bastante popular, sin embargo, en la cultura árabe no es muy habitual este tipo de bebidas a base de maíz, por ende, creemos que el lector árabe no está familiarizado con ellas.

En este ejemplo, los traductores han decidido traducir el culturema con el préstamo "الأتولي", y opinamos que el uso de esta técnica junto con la amplificación (nota a pie de página) es aceptable, porque acerca más la idea del culturema al lector, aunque en árabe ya existe un equivalente acuñado propuesto por el Diccionario Español - Árabe Al-Muín عصيذة من دقيق الذرة. 
TO: 100

- A usted ni quien le menoscabe lo hombre que es; pero me lleva la rejodida con ese hijo de la rechintola $\left.{ }^{*}\right)$ de su patrón.

${ }^{(*)}$ Rechintola: insulto; palabra formada probablemente sobre la base del verbo "chingar", que en México es especialmente utilizado para expresiones soeces.

\begin{tabular}{|c|c|c|}
\hline $\begin{array}{l}\text { TM1: } 60 \\
\text { Adaptación }\end{array}$ & 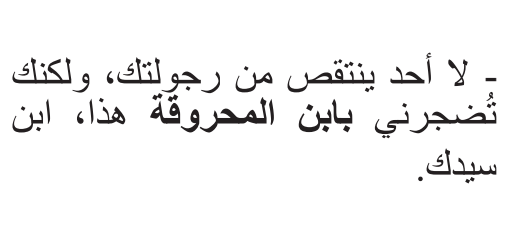 & $\begin{array}{l}\text { - A usted ni quien le } \\
\text { menoscabe lo hombre } \\
\text { que es, pero me fastidias } \\
\text { con este hijo de la } \\
\text { quemada de su patrón. }\end{array}$ \\
\hline $\begin{array}{l}\text { TM2: } 79 \\
\text { Reducción }\end{array}$ & 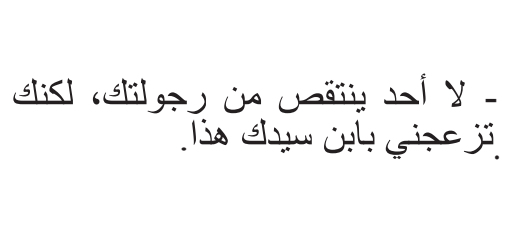 & $\begin{array}{l}\text { - A usted ni quien le } \\
\text { menoscabe lo hombre } \\
\text { que es, pero me molestas } \\
\text { con este hijo de su } \\
\text { patrón. }\end{array}$ \\
\hline $\begin{array}{l}\text { TM3: } 98 \\
\text { Adaptación }\end{array}$ & ثن ثائرتي لاحد يشك في رجولتلك، ولكن. & $\begin{array}{l}\text { A usted ni quien le } \\
\text { menoscabe lo hombre } \\
\text { que es, pero me estallo } \\
\text { de cólera con este hijo de } \\
\text { perro de su patrón. }\end{array}$ \\
\hline
\end{tabular}

En esta escena, Toribio Alderte, quien poseía tierras muy extensas constituía un obstáculo para Pedro Páramo que tenía como fin apoderarse de todas las tierras del pueblo después de la muerte de su padre don Lucas que dejó la familia en una situación financiera muy difícil.

La rechintola es una voz insultante con referencia a la rechingada en México. La lengua árabe no cuenta con un equivalente al culturema, por eso, los tres traductores han optado por frases hechas que tienen sentido peyorativo y despectivo en la lengua y cultura meta.

El TM2 no incluye la expresión, en cambio, el TM1 y el TM3 han mantenido el violento tono del culturema, y lo han traducido por "مبن الدحروقة" (hijo de la quemada) y por "مبن الكلب" (hijo del 
perro) respectivamente. Pensamos que las dos propuestas son per-

tinentes, y catalogamos la técnica como adaptación.

- Tilcuatazos

\section{TO: 164}

"De todos modos, 'los tilcuatazos' que se van a llevar estos locos", pensó.

\begin{tabular}{|c|c|c|}
\hline $\begin{array}{l}\text { TM1: } 143 \\
\text { Préstamo }\end{array}$ & هؤلاء الحمقى على للتىكواتات حالتي سيتلقاها & $\begin{array}{l}\text { "De todos modos, los } \\
\text { tilcuatazos que se van } \\
\text { a llevar estos locos", } \\
\text { pensó. }\end{array}$ \\
\hline $\begin{array}{l}\text { TM2: } 175 \\
\text { Préstamo }\end{array}$ & 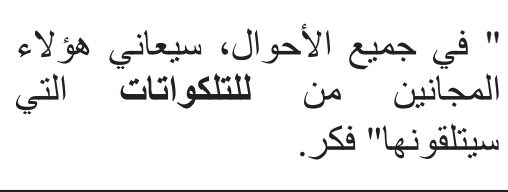 & $\begin{array}{l}\text { "De todos modos, los } \\
\text { tilcuatazos que se van } \\
\text { a llevar estos locos", } \\
\text { pensó. }\end{array}$ \\
\hline $\begin{array}{l}\text { TM3: } 172 \\
\text { Traducción literal }\end{array}$ & 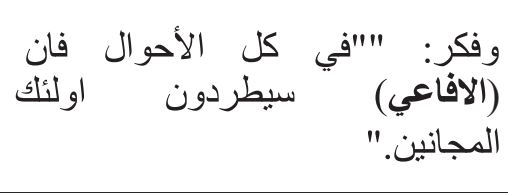 & $\begin{array}{l}\text { "De todos modos, (los } \\
\text { tilcuates) que se van } \\
\text { a llevar estos locos", } \\
\text { pensó. }\end{array}$ \\
\hline
\end{tabular}

En este ejemplo, estamos ante una palabra puramente mexicana que tiene sus raíces en la cultura náhuatl. Tilcuatazo proviene de la palabra tilcuate que designa una especie de víbora negra que ataca al hombre y a las demás serpientes.

Los diccionarios no recogen dicha palabra cuyo significado, probablemente, podría referirse a "golpes”. Los TM1 y TM2 lo han traducido mediante el préstamo "تلكو "تاتا" y el TM3 lo ha traspasado literalmente "لاعاعي", haciendo mención al significado original de la palabra origen tilcuate. 


\section{TO: 188}

Pasaste rozando con tu cuerpo las ramas del paraíso que está en la vereda y llevaste con tu aire sus últimas hojas.

\begin{tabular}{|c|c|c|}
\hline $\begin{array}{l}\text { TM1: } 175 \\
\text { Traducción literal } \\
+ \text { amplificación }\end{array}$ & 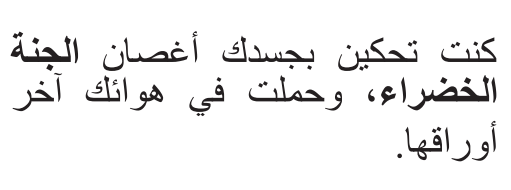 & $\begin{array}{l}\text { Rozaste con tu cuerpo } \\
\text { las ramas del paraíso } \\
\text { verde y llevaste con tu } \\
\text { aire sus últimas hojas. }\end{array}$ \\
\hline $\begin{array}{l}\text { TM2: } 212 \\
\text { Traducción literal }\end{array}$ & 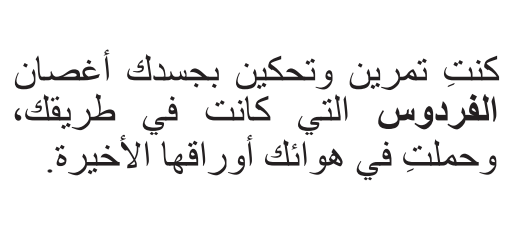 & $\begin{array}{l}\text { Pasaste rozando con tu } \\
\text { cuerpo las ramas del } \\
\text { paraíso que estaban en } \\
\text { tu vereda, y llevaste con } \\
\text { tu aire sus últimas hojas. }\end{array}$ \\
\hline $\begin{array}{l}\text { TM3: } 200 \\
\text { Traducción literal }\end{array}$ & 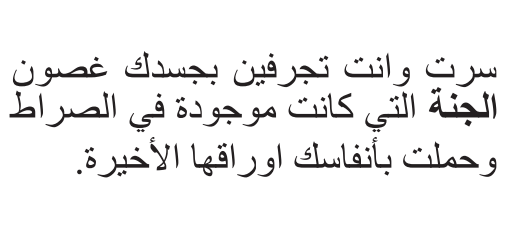 & $\begin{array}{l}\text { Pasaste rozando con tu } \\
\text { cuerpo las ramas del } \\
\text { paraíso que estaba en la } \\
\text { vereda, y llevaste con tu } \\
\text { aliento sus últimas hojas. }\end{array}$ \\
\hline
\end{tabular}

En este ejemplo, los traductores han optado por la traducción

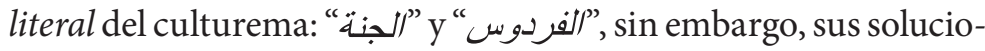
nes no son adecuadas, porque no reflejan el significado original de la palabra.

Paraíso es el nombre que en México se da al cinamomo, un árbol que se distribuye en el Caribe, Norteamérica y Oceanía, cuyo equivalente acuñado en árabe es الزنزلخت

Pensamos que las soluciones adoptadas por los tres textos se deben probablemente al hecho de que el nombre del árbol en el contexto podría, tal vez, referirse también al paraíso en su sentido literal. 


\section{TO: 178}

Cuando vio los $\operatorname{cocuyos}{ }^{(*)}$ cruzando otra vez sus luces, se dio cuenta que todos los hombres se habían ido.

${ }^{(*)}$ Cocuyo: insecto que de noche despide una luz bastante intensa.

\begin{tabular}{|c|c|c|}
\hline $\begin{array}{l}\text { TM1: } 162 \\
\text { Préstamo }+ \\
\text { Amplificación }\end{array}$ & 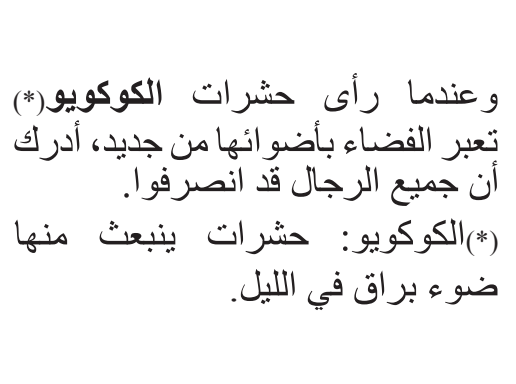 & $\begin{array}{l}\text { Cuando vio los cocuyos } \\
\text { cruzando otra vez con } \\
\text { sus luces, se dio cuenta } \\
\text { que todos los hombres se } \\
\text { habían ido. } \\
\text { Cocuyo }^{(*)} \text { : insecto que } \\
\text { de noche despide una luz } \\
\text { bastante intensa. }\end{array}$ \\
\hline $\begin{array}{l}\text { TM2: } 197 \\
\text { Generalización } \\
+ \text { Amplificación }\end{array}$ & 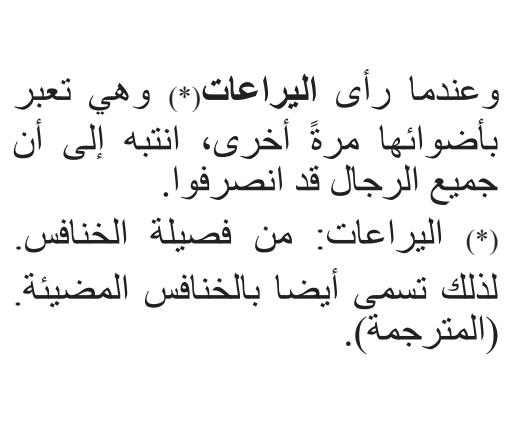 & $\begin{array}{l}\text { Cuando vio los lampíridos } \\
{ }^{*} \text { cruzando otra vez sus } \\
\text { luces, se dio cuenta que } \\
\text { todos los hombres se } \\
\text { habían ido. } \\
{ }^{*} \text { Lampíridos: son } \\
\text { escarabajos. Pertenecen } \\
\text { a la familia de los } \\
\text { coleópteros. (la traductora) }\end{array}$ \\
\hline $\begin{array}{l}\text { TM3: } 188 \\
\text { Generalización }\end{array}$ & واذبيائها مرة أخدى حشرات إنتبه اليراع ان تثاطع & $\begin{array}{l}\text { Cuando vio los lampíridos } \\
\text { cruzando otra vez sus luces, } \\
\text { se dio cuenta que todos los } \\
\text { hombres se habían ido. }\end{array}$ \\
\hline
\end{tabular}

En este ejemplo, constatamos que el TM2 y el TM3 han decidido emplear términos generales " البير/عات" y " ليراع" respectivamente, lo que ha llevado a una pérdida de información. En cambio, el TM1 ha transmitido la idea del texto original mediante el préstamo "الكوكوبيو" al que le ha añadido una nota a pie de página explicativa que clasificamos como una amplificación.

No cabe duda de que tanto las soluciones como las técnicas usadas son demasiado vastas para traspasar el término mexicano. 


\section{TO : 166}

Sólo se les oyó sorber el chocolate cuando les trajeron el chocolate, y masticar tortilla tras tortilla cuando les arrimaron los frijoles ${ }^{(*)}$.

$\left.{ }^{*}\right)$ Frijol: Amér., frejol. En México se pronuncia siempre así. Es uno de sus principales alimentos y aparece como remate obligado del almuerzo y de la cena.

\begin{tabular}{|c|c|c|}
\hline $\begin{array}{l}\text { TM1: } 145 \\
\text { Traducción } \\
\text { literal }+ \\
\text { Reducción }\end{array}$ & 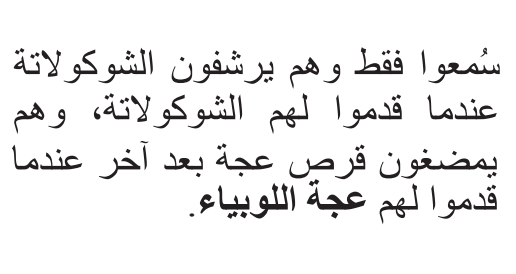 & $\begin{array}{l}\text { Sólo se les oyó sorber } \\
\text { el chocolate cuando les } \\
\text { trajeron el chocolate, } \\
\text { y masticar tortilla tras otra } \\
\text { cuando les dieron tortillas } \\
\text { de frijoles. }\end{array}$ \\
\hline $\begin{array}{l}\text { TM2: } 178 \\
\text { Traducción } \\
\text { literal }+ \\
\text { Reducción }\end{array}$ & 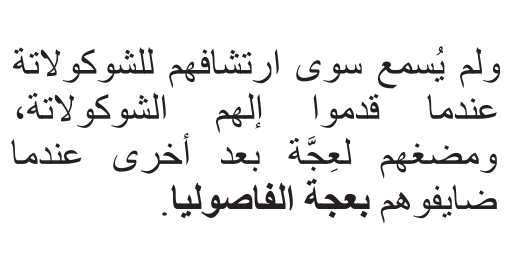 & $\begin{array}{l}\text { Sólo se les oyó sorber } \\
\text { el chocolate cuando les } \\
\text { trajeron el chocolate, } \\
\text { y masticar tortilla tras otra } \\
\text { cuando les dieron tortilla } \\
\text { de frijoles. }\end{array}$ \\
\hline $\begin{array}{l}\text { TM3: } 175 \\
\text { Traducción } \\
\text { literal }+ \\
\text { Reducción }\end{array}$ & 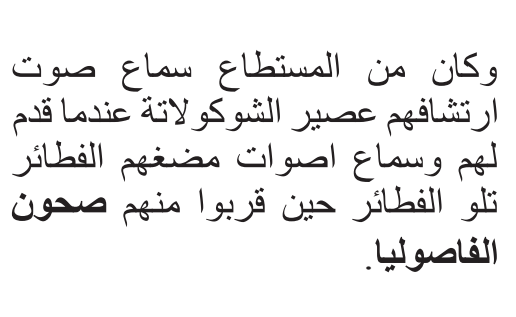 & $\begin{array}{l}\text { Era posible oír sorber el } \\
\text { zumo de chocolate cuando } \\
\text { se lo presentaron, y oír } \\
\text { masticar pasteles tras } \\
\text { pasteles cuando se les } \\
\text { acercaron los platos de } \\
\text { frijoles. }\end{array}$ \\
\hline
\end{tabular}

Al igual que el maíz, el frijol es un alimento muy importante en la mesa mexicana, y forma parte de la cultura gastronómica de México.

Según el DRAE, el término frijol en su forma plural equivale en México a alimento. El mismo significado lo confirma el Diccionario Breve de Mexicanismos, en el que figura que la palabra frijol en su forma plural hace referencia a comida o alimento.

Los tres textos meta han traducido el culturema literalmente

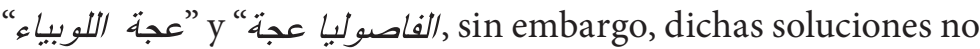
reflejan el significado del término, por eso, las catalogamos como traducción literal. 
- No dar agua ni al gallo de la pasión

TO: 167

- Éste "no le daría agua ni al gallo de la pasión".

\begin{tabular}{|c|c|c|}
\hline $\begin{array}{l}\text { TM1: } 147 \\
\text { Traducción literal }\end{array}$ & ــ هذا " لا يعطي ماء حتى لايك آلام & $\begin{array}{l}\text { Esto "no le daría agua ni } \\
\text { al gallo de los dolores de } \\
\text { Cristo". }\end{array}$ \\
\hline $\begin{array}{l}\text { TM2: } 180 \\
\text { Traducción literal }\end{array}$ & تـعاني هذا " لام النمسيحي معاءً حتى لو كنت & $\begin{array}{l}\text { - Esto "no le daría agua } \\
\text { aunque sufres los } \\
\text { dolores de Cristo". }\end{array}$ \\
\hline
\end{tabular}

TM3: 176

Creación

$$
\begin{aligned}
& \text { - Esto no sacia nuestra } \\
& \text { sed. }
\end{aligned}
$$

discursiva

No dar agua ni al gallo de la pasión es un refrán mexicano que designa una persona egoísta y excesivamente tacaña, que no hace favores ni da una ayuda económica ni al más necesitado.

El gallo de la pasión forma parte de la historia de la Cristiandad ya que tiene relación con Pedro, uno de los apóstoles de Jesús, que negó ser seguidor de su Maestro para evitar su detención y su crucifixión. Antes de su ejecución y en la última cena, Jesús anunció que sería traicionado por uno de sus discípulos, y Pedro se levantó para defenderse y asegurarle que él nunca lo haría, sin embargo, Cristo le contestó diciendo: "antes que el gallo cante dos veces, me negarás tres".

Es muy difícil traducir esta referencia cultural al árabe, no obstante, los traductores han intentado traspasarla mediante la tra-

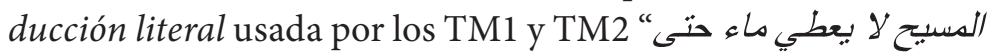

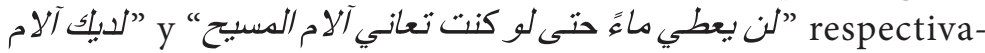

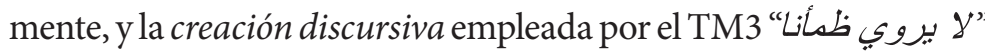
(no sacia nuestra sed), una solución adecuada que aunque no es su equivalente acuñado consigue transmitir la idea de la expresión original. 


\section{Conclusión}

La traducción de los culturemas necesita mucho esfuerzo y mucha creatividad por parte del traductor, dado que requiere que éste tenga la capacidad para encontrar las equivalencias culturales que trasmiten de forma adecuada la connotación y el mensaje del texto origen al lector meta.

En este artículo, nuestro objetivo es presentar un nuevo enfoque en los estudios de la traducción cultural representado por el nuevo término acuñado "culturema", así como presentar unos ejemplos en los que hemos analizado unos culturemas y sus correspondientes técnicas de traducción usadas por tres traductores árabes, con el fin de ofrecer una breve idea sobre la dificultad de traducir este tipo de elementos culturales, y también poner énfasis en la preparación del traductor y su uso de las fuentes de documentación, dos herramientas imprescindibles para una traducción adecuada.

Cabe señalar que la obra Pedro Páramo de Juan Rulfo es una buena puerta de entrada para estudiar la traducción de culturemas, ya que hemos encontrado un total de 116 elementos culturales referentes a la cultura mexicana y la vida cotidiana de los mexicanos del pueblo.

\section{Referencias bibliográficas}

Almāniy, S. (2013), Bìdrū Bārāmū, [Pedro Páramo], Dammam: Dār Ātar.

Gómez De Silva, G. (2003), Diccionario Breve de Mexicanismos. México D. F.: Academia Mexicana.

Hurtado Albir, A. (2001), Traducción y Traductología, Madrid: Ediciones Cátedra.

Ibrāhīm, M. (1990), Bìdrū Bārāmū, [Pedro Páramo], Bagdad: Dār al māmūn li taryama wanashr.

Katan, D. (1999), Translating Cultures, An Introduction for Translators, Interpreters and Mediators. Manchester: St. Jerome Publishing.

Luque Nadal, L. (2009), “Los culturemas: ¿unidades lingüísticas, ideológicas o culturales”, Language Design, 11, 93-120. 
Luque Toro, L. (2006), “De cómo influyen los aspectos socio-culturales en la traducción: The Accidental Tourist de Anne Tyler traducida al italiano", en P. Blanco García, A. Martino Alba (eds.), Traducción y Multiculturalidad, Madrid: Instituto Universitario de Lengua Modernas y Traductores, Universidad Complutense de Madrid, 211-218.

Martín Sánchez, M. (2010), Diccionario de Americanismos, Madrid: Santillana.

Mayoral, A. R. (1994), "La documentación en la traducción”, en J. De Agustín (ed.), Traducción, interpretación, lenguaje, Madrid: Cuadernos del Tiempo Libre, 107-118.

Molina Martínez, L. (2001), Análisis descriptivo de la traducción de los culturemas árabe- español, tesis Doctoral, Bellaterra: Universitat Autònoma de Barcelona.

Molina Martínez, L. (2006), El otoño del pingüino. Análisis descriptivo de la traducción de los culturemas, Castellò de la Plana: Publicacions de la Univesrsitat Jaume I.

Newmark, P. (1988), A Textbook of Translation, Hertfordshire: Prentice Hall International (UK) Ltd.

Nida, E. (1945), "Linguistics and Ethnology in Translation Problems", Word, 1, 194-208.

Nida, E. (1964), Toward a Science of Translating with Special Reference to Principles and Procedures involved in Bible Translating, Leiden: E. J. Brill.

Nord, C. (1991), Text Analysis in Translation, Amsterdam: Rodopi.

Nord, C. (1997), Translating as a Purposeful Activity. Functionalist Approaches Explained, Manchester: St. Jerome.

Reda, Y. (1996), Al-Muin: Diccionario Español-Árabe, Líbano: Librairie du Liban.

Renaud, R. (1997), Diccionario de Hispanoamericanismos, Madrid: Cátedra.

Rulfo, J. (1986), Pedro Páramo, Madrid: Cátedra.

Santamaría, L. (2001b), "Función y traducción de los referentes culturales en subtitulación”, en L. Lorenzo (ed.), Traducción subordinada (II): el subtitulado, Vigo: Publicacións da Universidade de Vigo, 237-248. 
'Șmat, S. (2013), Bīdrū Bārāmū, [Pedro Páramo], El Cairo: Al haya al 'āma li qoșūr ataqaāfa.

Vermeer, H. (1983), "Translation theory and linguistics”, en P. Roinila, R. Orfanos y S. Tirkkonen-Condit (eds.), Näkökohtia käänämisen tutkimuksesta, Joensuu: University of Joensuu, $1-10$.

Vidal Claramonte, C. (1995), "La cultura como unidad de traducción”, Pragmalingüística, 3/4, 187-203.

Vinay, J. y Darbelnet, J. (1958), Stylistique comparée du français et de l'anglais, Paris: Les éditions Didier.

Vlakhov, S. y Florin, S. (1970), "Neperevodimoe v perevode: realii”, Masterstvo perevoda, Moscow: Sovetskii pisatel, 432-456. 